\title{
Patterns of expressions of transforming growth factor and epidermal growth factor receptor in squamous cell lesions of the urinary bladder
}

\author{
M F Tungekar, J Linehan
}

\begin{abstract}
Aim-To investigate the patterns of expression of transforming growth factor $\alpha$ (TGF- $\alpha$ ) and epidermal growth factor receptor (EGFR) in squamous metaplasia and squamous cell carcinomas of the urinary bladder with and without schistosomiasis.

Methods-Immunohistochemical study of the expression of TGF- $\alpha$ and EGFR in squamous metaplasias $(n=12)$ and various grades of squamous cell carcinomas $(n=21)$ of the bladder with and without schistosomiasis.

Results-Focal cytoplasmic and membranous positivity for EGFR and TGF- $\alpha$ was seen in all cases of squamous metaplasia. The markers were diffusely coexpressed in a concordant pattern in areas of hyperplastic keratinising squamous metaplasia. A similar pattern of positivity was seen in verrucous carcinomas $(n=2)$ and well differentiated squamous carcinomas $(n=$ 6). Progressive loss of differentiation was associated with increasing loss of EGFR staining while TGF- $\alpha$ staining was retained. Squamous cell carcinoma in situ $(\mathbf{n}=2)$ showed focal positivity for TGF- $\alpha$ and EGFR. There were no differences in staining patterns between cases with and without schistosomiasis.
\end{abstract}

Conclusions-The coexpression of TGF- $\alpha$ and EGFR by well differentiated squamous cell carcinomas and hyperplastic keratinising squamous metaplasia is consistent with the active regulatory role exerted by this autocrine loop. There is regional absence of expression of EGFR but not of TGF- $\alpha$ in squamous cell carcinomas of lesser differentiation, suggesting heterogeneity of such control in these tumours. The focal expression of the two markers in

Accepted for publication 1 April 1998

Table 1 Cases studied

\begin{tabular}{|c|c|c|c|c|}
\hline \multirow[b]{2}{*}{ Diagnosis } & \multicolumn{3}{|c|}{ Number of cases ${ }^{1}$} & \multirow[b]{2}{*}{ Stage } \\
\hline & Kuwait & London & Total & \\
\hline Normal urothelium & 5 & 5 & 10 & - \\
\hline Urothelial hyperplasia & $3(3)$ & $2(2)$ & $5(5)$ & - \\
\hline Squamous metaplasia ${ }^{2}$ & $9(7)$ & $3(1)$ & $12(8)$ & - \\
\hline \multicolumn{5}{|l|}{ Squamous cell carcinomas } \\
\hline Verrucous carcinoma & $2(2)$ & - & $2(2)$ & pT1 \\
\hline Well differentiated $^{3}$ & $6(4)$ & - & $6(4)$ & pT1 $(n=5), p T 2(n=1)$ \\
\hline Moderately differentiated ${ }^{4}$ & $5(4)$ & $3(1)$ & $8(5)$ & pT3a \\
\hline Poorly differentiated & $3(1)$ & - & $3(1)$ & pT3a \\
\hline
\end{tabular}

${ }^{1}$ Numbers in parentheses refer to cases with schistosomiasis.

${ }^{2}$ Including four with foci of hyperplastic keratinising squamous metaplasia

${ }^{3}$ Including four with foci of hyperplastic keratinising squamous metaplasia.

${ }^{4}$ Including two with foci of squamous cell carcinoma in situ. squamous cell carcinomas in situ indicates a possible second pathway of oncogenesis for less differentiated tumours. These observations may have important implications for the effectiveness of putative growth factor based treatments.

(f Clin Pathol 1998;51:583-587)

Keywords: bladder; squamous cell carcinoma; transforming growth factor $\alpha$; epidermal growth factor

Squamous cell carcinomas of the bladder are uncommon in the developed countries, where they are mostly seen in elderly people or with chronic cystitis. ${ }^{12}$ In areas endemic for urinary schistosomiasis these tumours are the commonest type of bladder malignancy and are usually associated with squamous metaplasia. ${ }^{3-6}$ Pathology of vesical squamous lesions has been well documented in several series. ${ }^{467}$ Nearly all malignancies seen in association with squamous metaplasia are pure squamous cell carcinomas, regardless of schistosomal infestation. ${ }^{1-489}$ On the other hand the malignant potential of squamous metaplasia in general is difficult to assess because only a few studies have defined its different phenotypes. $^{28}$ The non-keratinising "vaginal" type of squamous metaplasia commonly seen in the trigone of the female bladder is not regarded as sinister. ${ }^{10}$ Even hyperplastic keratinising squamous metaplasia (also known as basal cell hyperplasia), believed to be of ominous significance, has an unpredictable course. Thus its relation to squamous cell carcinomas was not supported by Morgan and Cameron, ${ }^{8}$ and although Benson et al identified simultaneous or subsequent squamous malignancies in $28 \%$ of cases over a period of 30 years, $58 \%$ of such metaplasias were not associated with tumours. $^{2}$ Therefore this type of squamous metaplasia may not be biologically homogeneous and further investigations may identify subspecies with differing malignant potentials. The subjective descriptions of grades of dysplasias and in situ malignant phase of squamous cell lesions further compound the difficulties, ${ }^{45}$ and their infrequent recognition in biopsy material precludes large prospective studies.

Most studies in this area have relied on using routine staining techniques to describe the morphology of these lesions; only a few have used immunohistochemical techniques to investigate the expression of growth factors and various differentiation markers and thereby explore the relations that might exist between squamous metaplasia and carcinoma. ${ }^{3} 91112$

Transforming growth factor $\alpha\left(\mathrm{TGF}_{-} \alpha\right)$ has a wide range of biological activities including 
Table 2 Summary of immunopositivity for transforming growth factor a (TGF-a) and epidermal growth factor receptor (EGFR)

\begin{tabular}{|c|c|c|c|c|c|}
\hline \multirow[b]{2}{*}{ Lesion } & \multicolumn{4}{|c|}{ Immunopositivity } & \multirow[b]{2}{*}{ Concordance $^{*}$} \\
\hline & $T G F-a / c$ & $T G F-\alpha / m$ & $E G F R / c$ & $E G F R / m$ & \\
\hline Squamous metaplasia & Focal +/++ & Focal +/++ & - & Focal + & Absent \\
\hline Hyperplastic keratinising squamous metaplasia & Diffuse ++ & Diffuse ++ & _- & Diffuse +++ & Present \\
\hline Squamous cell carcinoma in situ & Focal ++ & Focal ++ & & Focal ++ & Mixed $\dagger$ \\
\hline \multicolumn{6}{|l|}{ Squamous cell carcinomas: } \\
\hline Verrucous carcinoma & Diffuse +++ & Diffuse +++ & - & Diffuse +++ & Present \\
\hline Well differentiated & Diffuse +++ & Diffuse +++ & - & Diffuse +++ & Present \\
\hline Moderately differentiated & Diffuse ++ & Diffuse ++ & - & Regional & Mixed $\dagger$ \\
\hline Poorly differentiated & Diffuse ++ & Diffuse ++ & Focal + & Regional ++ & Mixed $†$ \\
\hline
\end{tabular}

${ }^{\star}$ Refers to the coexpression of TGF- $\alpha$ and EGFR in the same cell.

†Refers to regional loss of concordant pattern of staining.

regulation of cell growth and differentiation of self renewing epithelia; it acts as a paracrine growth factor through its interaction with epidermal growth factor receptor (EGFR). ${ }^{13}$ This ligand-receptor combination also constitutes a potent autocrine loop that is implicated in the oncogenesis of native and metaplastic squamous epithelium. ${ }^{14-18}$ In particular there is evidence that the expression of TGF- $\alpha$ and EGFR may be upregulated in the squamous epithelium adjacent to squamous cell

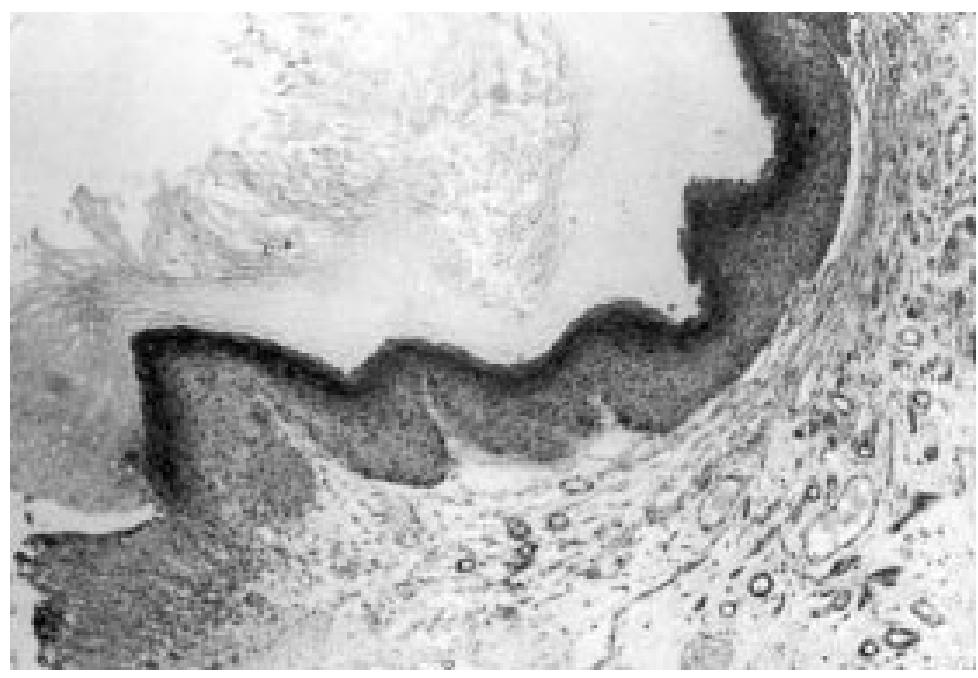

Figure 1 Squamous metaplasia with keratinisation. TGF-a staining shows focal labelling $(T G F-a / c+$ and $m+)$, more intense in superficial layers. (Magnification $\times 74$.)

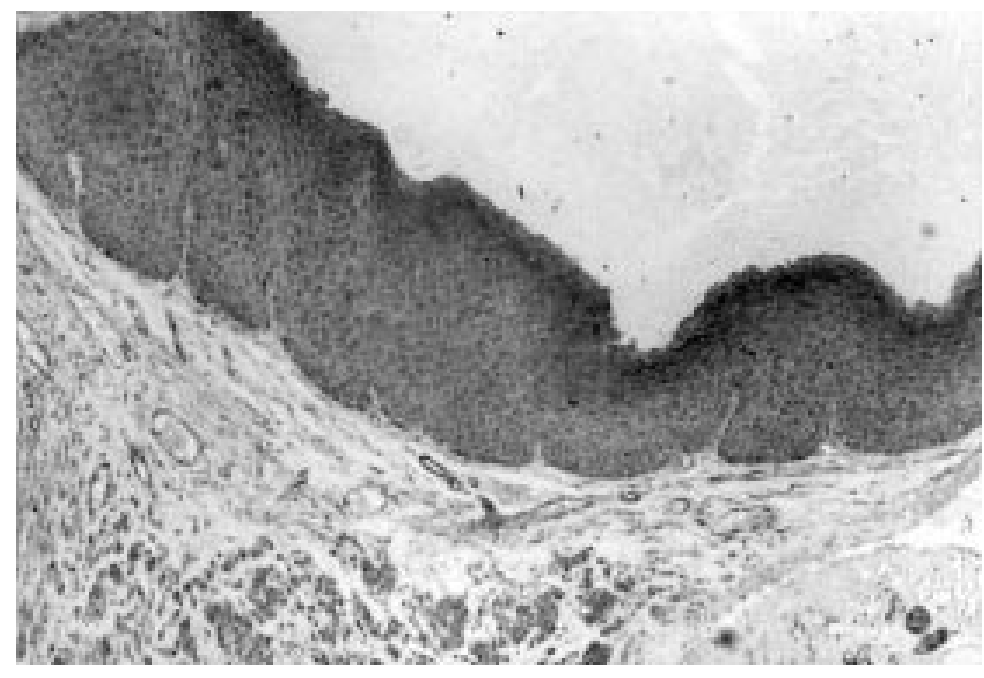

Figure 2 Hyperplastic keratinising squamous metaplasia displays full thickness $T G F-a / c+++$ and focal $T G F-a / m+$ staining. (Magnification $\times 74$.) carcinoma. $^{1920}$ Since the relevance of this important autocrine loop in squamous metaplasias and squamous cell carcinoma of bladder has not been investigated, we performed this immunohistochemical study of TGF- $\alpha$ and EGFR expression to assess their possible role in the multistep process of carcinogenesis in a range of vesical squamous cell lesions. Kamel et al had investigated the presence of c-erbB-2 oncoprotein in squamous cancers of bladder: positivity was found in three of 15 tumours with schistosomiasis and in one of seven tumours without. ${ }^{11}$ Since c-erbB-2 is a proto-oncogene that shares sequence homology with EGFR, we decided to include cases with and without schistosomiasis in this study. ${ }^{21}$

\section{Methods}

Thirty one cases of squamous metaplasias and squamous cell carcinomas were selected from the files of Mubarak Al-Kabeer Hospital, Kuwait, and St Thomas's Hospital, London as outlined in table 1. Cases of vaginal type of squamous metaplasias of female trigones were omitted. Schistosomiasis was identified in eight of the 12 squamous metaplasias and 12 of the 19 carcinomas. All 12 cases of squamous metaplasias and 18 of carcinomas were males. The ages for metaplasia cases ranged between 39 and 75 years and those for carcinomas between 43 and 75 years.

Haematoxylin and eosin stained sections were used to classify and stage squamous cell carcinomas according to the criteria used by the World Health Organisation and International Union against Cancer, as summarised in table $1 .{ }^{22}$ Four cases each of well differentiated carcinomas and of pure metaplasia contained foci of hyperplastic keratinising squamous metaplasia. Two of the 21 squamous cell carcinomas were verrucous in type. Two of the moderately differentiated carcinomas had adjacent foci of in situ malignancy. Three cases of schistosomal cystitis with urothelial hyperplasia without metaplasia were also included. Ten specimens of urothelium from bladders free of lesions were used as controls.

The tissue samples used were formalin fixed and routinely processed. Immunohistochemical staining was performed using standard streptavidin-biotin complex technique. For EGFR staining, antigen retrieval by microwave pretreatment for 10 minutes in $0.01 \mathrm{M}$ citrate buffer at $\mathrm{pH} 6$ in a domestic microwave oven 


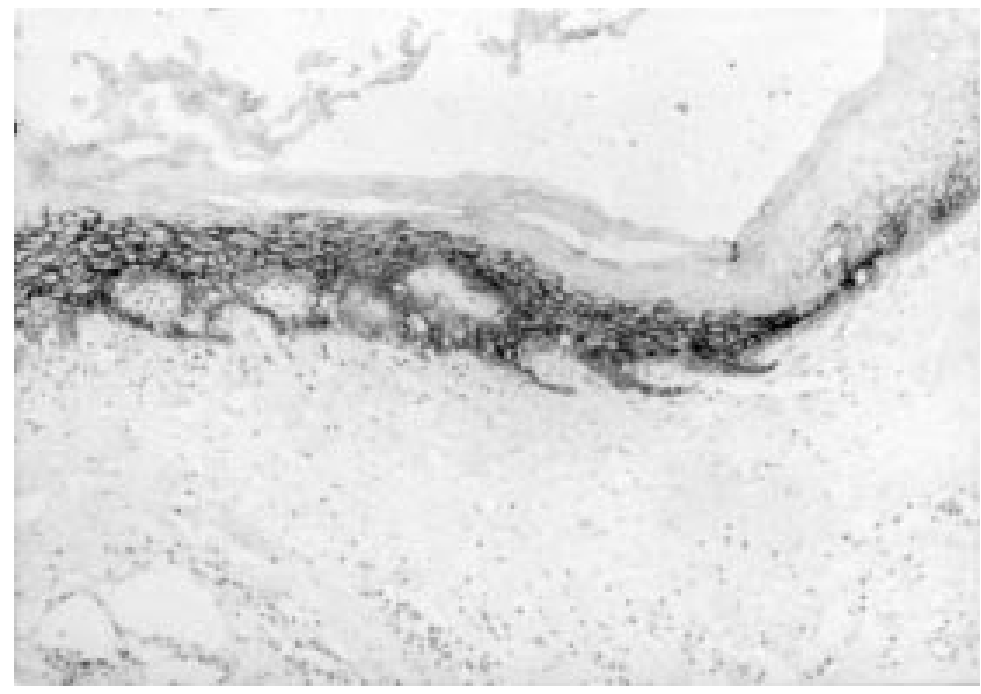

Figure 3 Same case as fig 2. Hyperplastic keratinising squamous metaplasia shows diffuse $E G F R / m+++$ in suprabasal layers including entire prickle cell layer. (Magnification $\times 82$.)

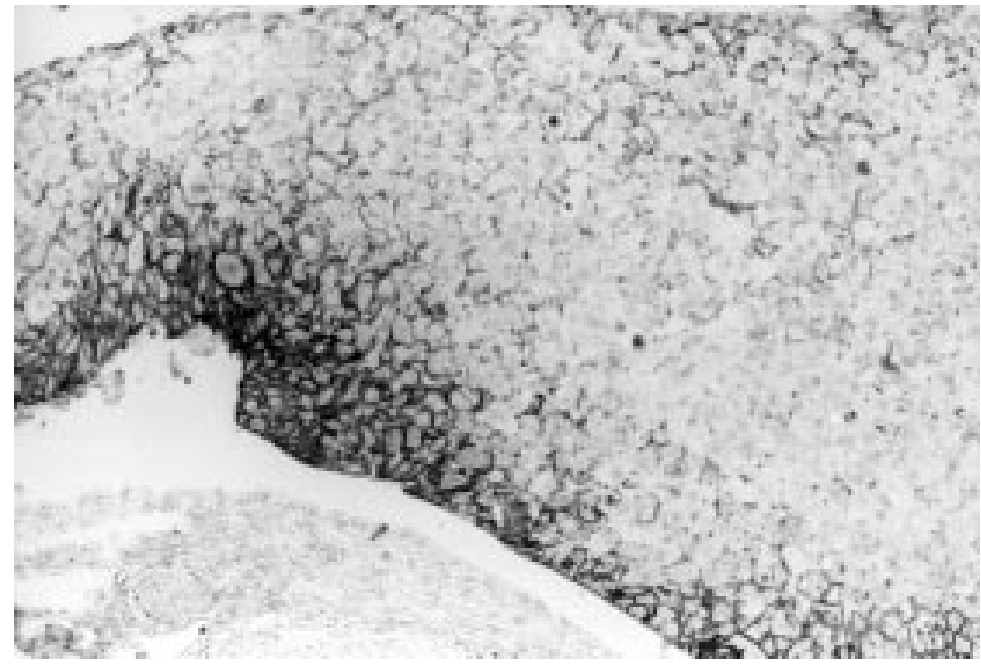

Figure 4 Focal labelling for EGFR/c+ and $m+$ in the squamous cell carcinoma in situ. (Magnification $\times 149$.)
The coexpression of the markers by the same cell was recorded as concordance of expression, which was assessed in sequential sections stained for each marker separately. For both markers the strength of cellular immunoreactivity was scored semiquantitatively as mild $(+)$, moderate $(++)$, or strong $(+++)$. For instance moderate degree of positivity for TGF- $\alpha$ in the cytoplasm and on cell membranes was recorded as TGF- $\alpha / \mathrm{c}++$ and $\mathrm{m}++$. For carcinomas, the extent of staining was assessed after counting at least 500 cells and recorded as focal (up to $10 \%)$, regional (10\% to $50 \%$ ), and diffuse (more than 50\%).

For metaplasias the positivity was assessed in relation to the superficial, prickle cell, and basal layers of the squamous epithelium.

\section{Results}

In the control urothelium, faint focal staining for both markers was observed: superficial layers were TGF- $\alpha / \mathrm{c}+$ and $/ \mathrm{m}+$ and basal layers were $\mathrm{EGFR} / \mathrm{m}+$. Positive diffuse labelling for TGF- $\alpha / \mathrm{c}++$ and $\mathrm{m}++$ in the endothelium and smooth muscle cells was also evident. In schistosomal cystitis without metaplastic changes, staining for $\mathrm{TGF}-\alpha / \mathrm{c}++$ and $\mathrm{EGFR} / \mathrm{m}++$ was seen focally in hyperplastic urothelium.

\section{SQUAMOUS METAPLASIAS}

Keratinisation of varying degrees was seen in all squamous metaplasias (table 2). All examples of squamous metaplasia in this study showed labelling for TGF- $\alpha / \mathrm{c}+$ and $\mathrm{m}+$ in superficial layers that was intense $(++)$ in keratinised areas (fig 1 ) and for EGFR/m++ in basal layers. In all eight examples of squamous metaplasia showing hyperplastic keratinising squamous metaplasia, the staining for TGF- $\alpha$ / $\mathrm{c}++$ was seen in all layers and for TGF- $\alpha / \mathrm{m}+$ focally (fig 2), and staining for $\mathrm{EGFR} / \mathrm{m}+++$ was seen in the widened prickle cell layer (fig 3).

(840 W) was carried out. The primary mouse monoclonal antibodies were applied overnight at $4^{\circ} \mathrm{C}$. These were anti-TGF- $\alpha$ (Ab-2, clone 213-94, Cambridge BioScience, Cambridge, UK) at a dilution of $1: 150$ and anti-EGFR (NCL-EGFR, Novocastra Laboratories, Newcastle upon Tyne, UK) at a dilution of 1:60, which bind to extracellular domains of TGF- $\alpha$ and human EGFR respectively. The antiEGFR antibody (NCL-EGFR) reacts with unbound EGFR as well as the receptor bound to its ligand. For negative controls irrelevant antibodies of the same IgG subclasses were used, as well as substitution of the primary antibody by phosphate buffered saline. Normal gastric mucosa was used as a positive control.

ASSESSMENT OF IMMUNOSTAINING

For both markers, immunoreactivity in the cytoplasm and cell membranes was looked for and was recorded as suffixes /c and $/ \mathrm{m}$ for each marker. Absence of positivity at both the sites was interpreted as a negative result. Attention was paid to the pattern of distribution of the label in different layers and parts of the lesions.

\section{SQUAMOUS CELL CARCINOMAS}

In the two cases of squamous cell carcinoma in situ, there was focal staining for $\mathrm{TGF}-\alpha / \mathrm{c}++$ and $\mathrm{m}++$ and $\mathrm{EGFR} / \mathrm{m}++$ in all layers of the epithelium (table 2; fig 4).

In verrucous carcinomas, a concordant staining for $\mathrm{TGF}-\alpha / \mathrm{c}+++$ and $\mathrm{m}+++$ and $\mathrm{EGFR} / \mathrm{m}+++$ was seen in tumour cells- that is, in sequential sections the two markers were expressed by same cells (fig 5 ). In the conventional types of squamous cell carcinoma, the well differentiated tumours showed a similar pattern of staining. In moderately differentiated tumours, diffuse $\mathrm{TGF}-\alpha / \mathrm{c}+++$ expression was generally retained (fig 6); however, EGFR/ $\mathrm{m}++$ expression was regional, seen only in the better differentiated areas and was either faint or lost in adjacent poorly differentiated areas (fig 7). This resulted in a mixed pattern with loss of the concordant pattern of coexpression for the two markers over large areas. The patterns of staining showed no correlation with presence of schistosomiasis, and in moderately and poorly differentiated carcinomas, with stage of the tumour. 

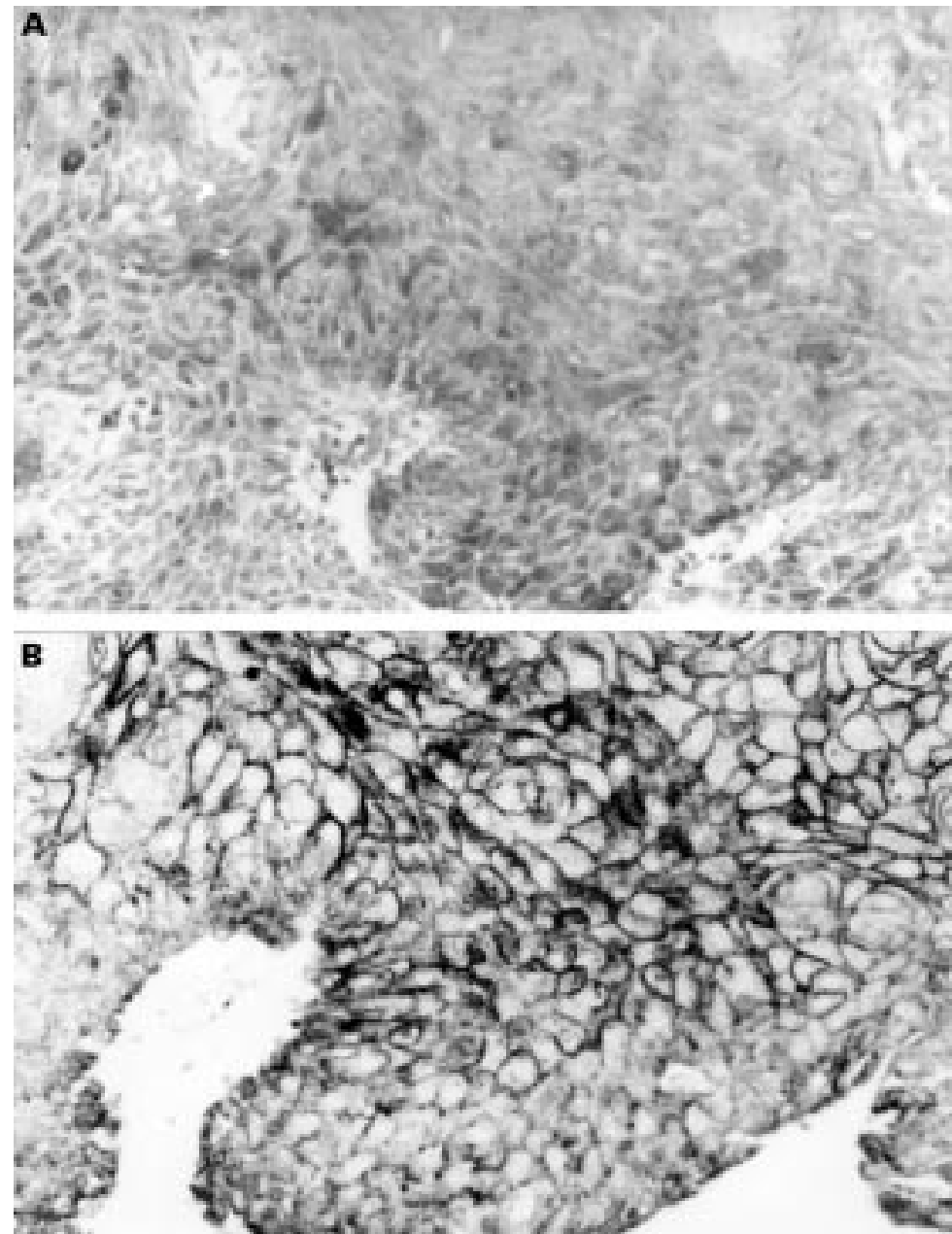

Figure 5 Verrucous squamous cell carcinoma showing diffuse "concordant" pattern of labelling for $T G F-a / c+++$ and $m+++$ (panel $A)$, and $E G F R / m++($ panel $B)$. (Magnifications $\times 149$.)

\section{Discussion}

The mildly increased expression of TGF- $\alpha$ and EGFR in the non-hyperplastic metaplastic squamous epithelium possibly reflects the paracrine role of these molecules; however, their marked upregulation confined to areas of hyperplastic keratinising squamous metaplasia indicates an active TGF- $\alpha$ /EGFR autocrine loop and may identify a subtype of this variety of squamous metaplasia. Although the numbers involved are small and the possibility of sampling error remains, the consistently concordant expression of TGF- $\alpha$ and EGFR in verrucous carcinomas, well differentiated areas of squamous cell carcinomas, and hyperplastic keratinising squamous metaplasia defines a continuum of well differentiated proliferative squamous cell lesions. A similar pattern has been described in cutaneous keratocanthomas. ${ }^{24}{ }^{25}$ Grandis et al, in their studies of squamous cell carcinomas of the head and neck region, have shown that both the neoplastic and non-neoplastic mucosa show an upregulation in synthesis of TGF- $\alpha$ and EGFR which may explain the frequent synchronous and metachronous malignancies of that mucosa, although the excess synthesis of these molecules is apparently not limited to hyperplastic mucosa in their material. ${ }^{19}{ }^{20}$ Our findings indi- cate that increased expression of TGF- $\alpha$ and EGFR is a feature of early stages in neoplastic transformation of squamous epithelium, and TGF- $\alpha /$ EGFR positive hyperplastic keratinising squamous metaplasia is possibly the earliest manifestation of that functional state. This also suggests that this type of metaplasia is likely to progress to well differentiated squamous cell carcinoma; however, such a progression may not be inevitable and may be modulated by other factors. In this context, the patchy staining for these markers obtained in squamous cell carcinoma in situ may suggest a second pathway that contributes to evolution of the less well differentiated invasive squamous cell carcinomas. This possibility needs to be validated by studies that include a larger number of in situ lesions.

Our observation of the general increase in expression of TGF- $\alpha$ and EGFR by squamous cell carcinomas is in agreement with similar findings for these tumours at other sites. ${ }^{19202526}$ However, we believe that the topography of this expression within individual tumours is significant. Thus in contrast to the concordant labelling for the two markers in verrucous carcinomas and their well differentiated counterparts, there was loss of EGFR expression in the less differentiated areas of tumours while TGF- $\alpha$ labelling was generally retained, albeit at a lower intensity. The loss of concordance between these two markers in squamous cell carcinomas was associated with poor differentiation. The reasons for this feature are not clear. Interaction between TGF- $\alpha$ and EGFR is followed by internalisation and degradation of the ligand-receptor complex, which may be accelerated in poorly differentiated carcinomas. ${ }^{27}$ However, this should result in similar degrees of cytoplasmic positivity for both. This loss of EGFR expression probably coincides with the emergence of autonomous clones of tumour cells that have escaped from regulatory control and are less susceptible to control by the TGF- $\alpha / E G F R$ axis, which would explain the excess of TGF- $\alpha$. These observations are in agreement with those made in cell lines from squamous cell carcinomas ${ }^{27}$ and in oesophageal tumours, where marked regional variations in EGFR expression were associated with an aggressive course. ${ }^{18}$ If these assumptions are true, then the influence of TGF- $\alpha /$ EGFR autocrine loop may only be effective in the early phases of carcinogenesis of well differentiated tumours.

The absence of EGFR expression may be one of the many significant features associated with increasingly aggressive tumour phenotype. This finding may have important implications for the proposed growth factor based treatments, since these may at best have only a palliative effect on moderate to poorly differentiated squamous cell carcinomas. ${ }^{28}$ This fact also underlines the need to examine biopsy material to look for the extent of expression of EGFR before such treatments are contemplated. Since interaction between growth factors and their ligands is often very complex, this hypothesis needs to be confirmed in a larger prospective study that should include investigations of tumour suppressor genes, 


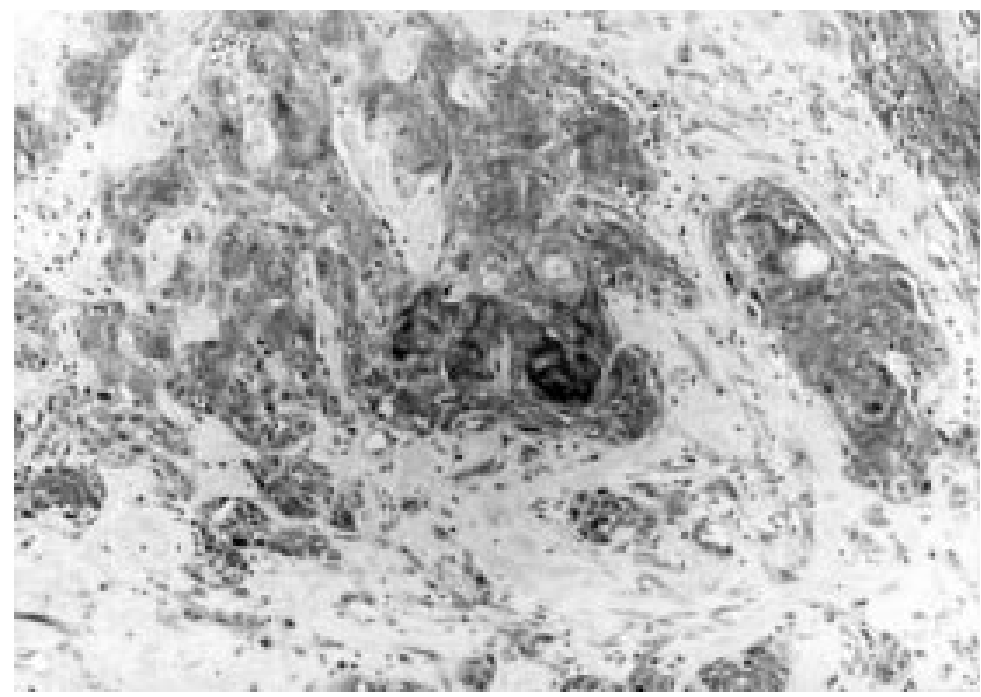

Figure 6 Diffuse TGF- $\alpha / c++$ and $m++$ staining of moderate and poorly differentiated areas of squamous cell carcinoma. (Magnification $\times 82$.)

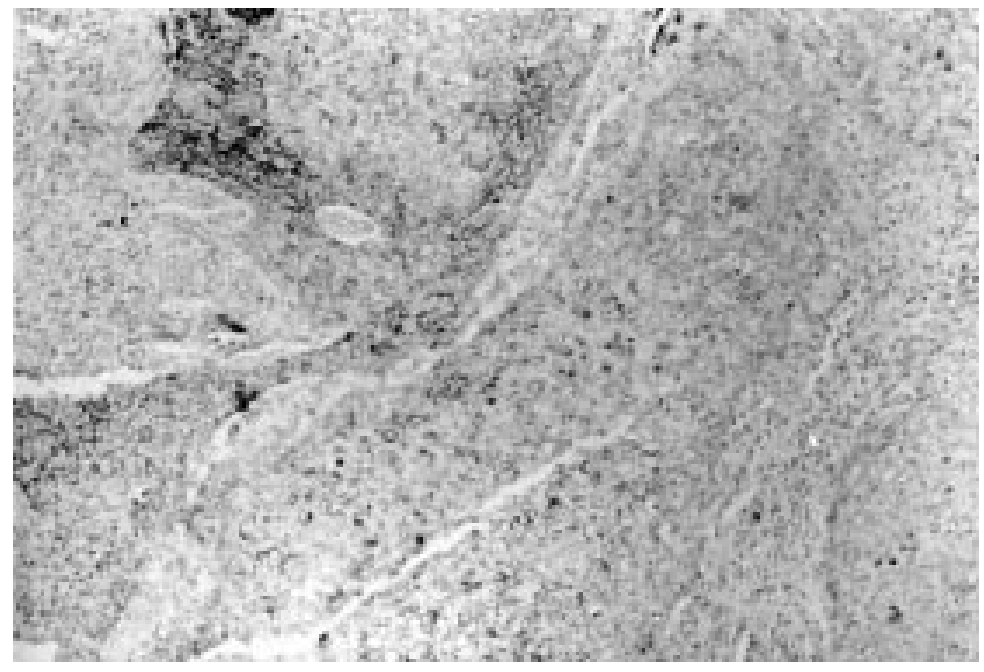

Figure 7 A poorly differentiated squamous cell carcinoma shows regional pattern of staining for EGFR/m++ and $c+$ (upper and lower left) with large areas of intervening tumour unstained. (Magnification $\times 74$.)

proliferation markers, and other modulators of effects of TGF- $\alpha$ such as TGF- $\beta,{ }^{24}$ as well as survival data.

In summary, our findings suggest that the TGF- $\alpha / E G F R$ autocrine loop is active in hyperplastic keratinising squamous metaplasia and in the early stages of transformation of metaplastic squamous epithelium. They also suggest that coexpression of these molecules is a marker of well differentiated squamous cell neoplasia. Although detection of these molecules is unlikely to be of value in predicting the behaviour of the majority of squamous cell carcinomas, we have provided evidence that tumours of moderate to poor differentiation may include substantial cell populations that are not controlled by this ligand-receptor activity. These are unlikely to be amenable to treatments based on TGF- $\alpha$ or EGFR. Focal expression of TGF- $\alpha$ and EGFR in squamous cell carcinomas in situ may characterise the pathway leading to higher grades of invasive squamous cell carcinomas. Our results also suggest that the role of these molecules in oncogenesis of squamous cancer in bladder is unlikely to be influenced by the presence of schistosmiasis.

1 Rundle JS, Hart AJ, McGeorge A, et al. Squamous cell carcinoma of bladder. A review of 114 patients. Br $\mathcal{F}$ Urol 1982;54:522-6.

2 Benson RC, Swanson SK, Farrow GM. Relationship of leukoplakia to urothelial malignancy. $\mathcal{F}$ Urol 1984;131:507-11.

3 Tungekar MF, Gatter KC, Al-Adnani MS. Immunohistochemistry of cytokeratin proteins in squamous and transitional cell lesions of the urinary tract. $\mathcal{f}$ Clin Pathol transitional cell lesio

4 El-Bolkainy MN, Mokhtar NM, Ghoneim MA, et al. The impact of schistosomiasis on the pathology of bladder carcinoma. Cancer 1981;48:2643-8.

5 Khafagy MM, El-Bolkainy MN, Mansour MA. Carcinoma of the bilharzial urinary bladder. A study of the associated mucosal lesions in 86 cases. Cancer 1972;30:150-9.

6 Cook-Mozaffari P. East Africa and Central Africa. In: Howe GM, ed. Global geocancerology. A world geography of human cancers. London: Churchill-Livingstone, 1986:331-7.

7 Sakamoto N, Tsuneyoshi M, Enjoji M. Urinary bladder carcinoma with a neoplastic squamous component: a mapping study of 31 cases. Histopathology 1992;21:135-41.

8 Morgan R, Cameron K. Vesical leukoplakia. Br f Urol 1980; 52:96-100.

9 Tungekar MF, Heryet A, Gatter KC. The L1 antigen and squamous metaplasia in the bladder. Histopathology 1991; 19:245-50.

10 Widran J, Sanchez R, Gruhn J. Squamous metaplasia of the bladder: a study of 450 patients. $\mathcal{F}$ Urol 1974;112:479-82.

11 Kamel D, Soini Y, Nuorva K, et al. p53 and c-erbB-2 expression in schistosomal urinary bladder carcinomas and schistosomal cystitis with premalignant lesions. Virchows Arch (Pathol Anat) 1994;424:349-55.

12 Fukushima S, Ito N, El-Bolkainy $\mathrm{MN}$, et al. Immunohistochemical observations of keratins, involucrin and epithelial membrane antigen in urinary bladder carcinomas from membrane antigen in urinary bladder carcinomas from Arch (Pathol Anat) 1987;411:103-15.

13 Gangarosa LM, Dempsey PJ, Damstrup L, et al. Transforming growth factor-alpha. Baillieres Clin Gastroenterol 1996; 10:49-63.

14 Grant JJ, Howes G, McKee PH. Transforming growth factor-alpha expression in in situ epidermal neoplasia. Clin Exp Dermatol 1995;20:208-12.

15 Jasonni VM, Amadori A, Santini D, et al. Epidermal growth factor receptor (EGF-R) and transforming growth factor alpha (TGFA) expression in different endometrial cancers. Anticancer Res 1995;15:1327-32.

16 Konishi I, Ishikawa Y, Wang SY, et al. Expression of transforming growth factor-alpha in the normal cervix and in benign and malignant lesions of the uterine cervix [comments]. Br f Obst Gynaecol 1994;101:325-9.

17 Ergun S, Zheng X, Carlsoo B. Expression of transforming growth factor-alpha and epidermal growth factor receptor in middle ear cholesteatoma. Am f Otol 1996;17:393-6.

18 Yano $\mathrm{H}$, Shiozaki H, Kobayashi K, et al. Immunohistologic detection of the epidermal growth factor receptor in human esophageal squamous cell carcinoma. Cancer 1991;67:91-8.

19 Grandis JR, Tweardy DJ. Elevated levels of transforming growth factor alpha and epidermal growth factor receptor messenger RNA are early markers of carcinogenesis in head and neck cancer. Cancer Res 1993;53:3579-84.

20 Grandis JR, Melhem MF, Barnes EL, et al. Quantitative immunohistochemical analysis of transforming growth factor-alpha and epidermal growth factor receptor in patients with squamous cell carcinoma of the head and patients with squamous $1996 ; 78: 1284-92$.

21 Yamamoto T, Ikawa S, Akiyama T, et al. Similarity of protein encoded by the human c-erbB-2 gene to epidermal growth factor receptor. Nature 1986;319:230-4.

22 Murphy WM, Bruce Beckwith J, Farrow GM, eds. Atlas of tumor pathology, third series, fascicle 11: Tumours of kidney, bladder and related urinary structures. Washington DC: Armed Forces Institute of Pathology, 1994:193-254.

23 Groves RW, Allen MH, MacDonald DM. Abnormal expression of epidermal growth factor receptor in cutaneous epithelial tumours. F Cutan Pathol 1992;19:66-72.

24 Ho T, Horn T, Finzi E. Transforming growth factor alpha expression helps to distinguish keratoacanthomas from squamous cell carcinomas. Arch Dermatol 1991;127:116771 .

25 Yoshida K, Kuniyasu H, Yasui W, et al. Expression of growth factors and their receptors in human esophageal carcinomas: regulation of expression by epidermal growth factor and transforming growth factor alpha. $\mathcal{F}$ Cancer Res Clin Oncol 1993;119:401-7.

26 Bergler W, Petroianu G, Juncker C, et al. Correlation of transforming growth factor alpha and epidermal growth factor receptor in oropharyngeal carcinomas. Acta OtoLaryngol 1996;116:486-9.

27 Partridge, M, Green, MR, Langdon, JD, et al. Production of TGF-alpha and TGF-beta by cultured keratinocytes, skin and oral squamous cell carcinomas-potential autocrine regulation of normal and malignant epithelial cell proliferation. Br F Cancer 1989;60:542-58.

28 Eccles SA, Modjtahedi H, Box G, et al. Significance of the c-erbB family of receptor tyrosine kinases in metastatic cancer and their potential as targets for immunotherapy. Invasion Metastasis 1994;14:337-48. 